\title{
Influência da leucoaférese terapêutica sobre parâmetros clínicos e hematológicos de equinos com sepse induzida por modelo de oligofrutose
}

Odael Spadeto Junior ${ }^{[a]}$, Alvaro de Paula Lage de Oliveira ${ }^{[b]}$, Cahue Francisco Rosa Paz $z^{[b]}$, Isabelle Marina Colen Fonseca ${ }^{[b]}$, Sergio da Silva Rocha Júnior ${ }^{[b]}$, Fabíola de Oliveira Paes Leme $e^{[b]}$, Marília Martins Melo ${ }^{[b]}$, Betânia Souza Monteiro ${ }^{[a]}$, Rafael Resende Faleiros ${ }^{[b]}$

\footnotetext{
[a] Universidade Vila Velha (UVV-ES), Vila Velha, ES, Brasil

[b] Universidade Federal de Minas Gerais (UFMG), Belo Horizonte, MG, Brasil
}

*Autor correspondente

e-mail: odaeljr@hotmail.com

\section{Resumo}

Os leucócitos possuem um papel importante na Síndrome da Resposta Inflamatória Sistêmica (SIRS), e a infiltração dessas células no tecido lamelar, causando destruição, já está bem documenta nos casos de laminite desencadeada pela sepse. O objetivo foi avaliar o efeito da remoção de leucócitos circulantes, por meio de protocolo de leucoaférese, sobre os parâmetros clínicos e hematológicos de equinos com quadro séptico induzido pelo modelo oligofrutose. A metodologia experimental foi aprovada pelo Comitê de Ética Sobre Experimentação Animal da UFMG (CETEA/UFMG 281/2013). Foram utilizados doze equinos, fêmeas, sem raça definida, com idade média de 10,5 \pm 5 anos, pesando $430 \pm 35 \mathrm{~kg}$, escore corporal $6 \pm 1$ (escore de 1 a 9), sem histórico prévio de claudicação e divididos em dois grupos de seis animais cada (controle - CON e tratado - LEUCO). Os dois grupos receberam oligofrutose (1g/kg sid por três dias mais $10 \mathrm{~g} / \mathrm{kg}$ sid) via sonda gástrica para indução de sepse e laminite. Doze horas após, os animais do LEUCO foram submetidos à leucoaférese por sistema de fluxo contínuo com duplo acesso venoso. Os animais foram monitorados diariamente no período de sensibilização e nos tempos 6, 12, 18, 24, 36 e 60 horas pós-indução da laminite, seguidos imediatamente pela coleta de sangue. Todos os equinos desenvolveram hipermotilidade intestinal, diarreia e congestão de mucosa a partir de 12 horas após indução. Às 24 horas, foram observados sinais clínicos de SIRS (taquicardia, hipertermia e leucocitose) e disfunção de órgãos (aumento das concentrações sanguíneas de glucose, creatinina e enzimas hepáticas) apenas no grupo CON. Às 36 horas, todos os cavalos do grupo CON apresentaram sinais de choque séptico e foram eutanaziados. Ao contrário, todos animais do grupo LEU estavam vivos ao final do período experimental. Concluiu-se que o modelo de oligofrutose foi eficiente em produzir um quadro de sepse e suas complicações em equinos não tratados. A disfunção de órgãos e a morte relacionada ao choque séptico foram prevenidas pelo uso do protocolo de leucaférese. 
Nossos resultados indicam que a leucoaférese tem o potencial para ser incorporada no arsenal terapêutico contra endotoxemia e sepse em equinos.

Palavras-chave: Equinos. Leucócitos. Aférese. 